\title{
Steric Perturbation to a Channel Hydrate: The Limits of Isomorphism
}

\author{
Taylor A. Watts, Courtney E. Lee, Sara M. Niederberger, Jeffery A. Bertke, Jennifer A. \\ Swift* \\ Georgetown University, Department of Chemistry, $37^{\text {th }}$ and O Streets NW, Washington, \\ DC 20057-1227
}

\section{List of Tables/Figures}

\section{A. Characterization of Mixed Crystals of Thymine and Uracil (Ur)}

Figure S1. Representative micrographs of (a) TH, (b) $\mathbf{T H}-\mathbf{U r}_{\mathbf{5}}$, (c) $\mathbf{T H}-\mathbf{U r}_{\mathbf{1 0}}$, (d) $\mathbf{T H}-\mathbf{U} \mathbf{r}_{\mathbf{1 5}}$, (e) TH-Ur 20. All scale bars $=50 \mu \mathrm{m}$.

Figure S2. Representative ${ }^{1} \mathrm{H}$ NMR $\left(\mathrm{DMSO}-\mathrm{d}_{6}\right)$ data for dissolved $\mathbf{T H}-\mathbf{U r}_{\mathbf{5}}$. Hydrogen atoms in Ur at $\mathrm{C} 5$ and $\mathrm{C} 6$ have $\delta=5.44$ and 7.38, respectively. Integrated intensities were compared against the thymine peaks at $\delta=1.72$ and $\delta=7.24$. Average Ur occupancies in the hydrate lattices were used in the development of the X-ray structure models.

Figure S3. For material grown from solutions containing 5, 10, 15 and $20 \mathrm{~mol} \%$ uracil (A-D, respectively) the derivative method was used to determine when the greatest water loss occurs in TGA data. Weight losses decreasing from $~ 6.9(8) \%$ in $\mathbf{T H}-\mathbf{U r}_{\mathbf{5}}$ to $2.2(7) \%$ in $\mathbf{T H}-\mathbf{U} \mathbf{r}_{\mathbf{2 0}}$ were obtained. However, these values do not account for water loss during sample preparation or at lower temperatures in the TGA run.

Table S1. Average $\mathrm{T}_{\max }$ determined in $\mathbf{T H}-\mathbf{U} \mathbf{r}_{\mathbf{x}}$ crystals grown from aqueous solutions with 5-20 $\mathrm{mol} \% \mathrm{Ur}$.

\section{B. Characterization of Mixed Crystals of Thymine and 5-Ethyluracil (EUr)}

Figure S4. Representative micrographs of (a) TH, and mixed crystals grown from solutions with thymine and (b) $5 \mathrm{~mol} \% \mathrm{EUr}$, (c) $10 \mathrm{~mol} \%$ EUr, (d) $15 \mathrm{~mol} \%$ EUr and (e) $20 \mathrm{~mol} \%$ EUr. All scale bars $=50 \mu \mathrm{m}$.

Figure S5. Representative ${ }^{1} \mathrm{H}$ NMR $\left(\mathrm{DMSO}_{-} \mathrm{d}_{6}\right)$ data for dissolved TH-EUr $\mathbf{r}_{\mathbf{5}}$. The hydrogen atoms at C6 in thymine and EUr have $\delta=7.24$ and 7.19, respectively. Their relative integrated intensities were used in the development of the X-ray structure model. 
Figure S6. Representative ${ }^{1} \mathrm{H}$ NMR $\left(\mathrm{DMSO}^{-} \mathrm{d}_{6}\right)$ data for dissolved T-EUr $\mathbf{r}_{\mathbf{2 0}}$. The hydrogen atoms at $\mathrm{C} 6$ in thymine and EUr have $\delta=7.24$ and 7.19, respectively. Their relative integrated intensities were used in the development of the X-ray structure model.

Figure S7. Differential scanning calorimetry of bulk material prepared from solutions containing $0-20 \mathrm{~mol} \%$ EUr. The phase composition is indicated for each. All measurements were made at $5.0^{\circ} \mathrm{C} / \mathrm{min}$ in hermetically sealed aluminum pans.

Figure S8. Side by side comparison of (top) $\mathbf{T}-\mathbf{E} \mathbf{U} \mathbf{r}_{\mathbf{2 0}}$ and (bottom) 5-ethyluracil (refcode: BOLLIY). Two views of each structure are presented. The packing diagram on the left is viewed down the hydrogen bonded tape direction. The view on the right is normal to the (001) plane with the hydrogen bonded tapes aligned vertically. Space-filling is used to better illustrate the differences in the packing of the 5-ethyl substituents. 


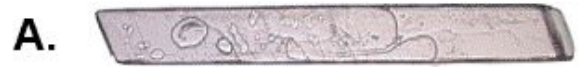

B.

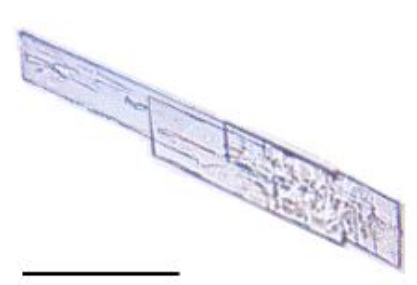

D.

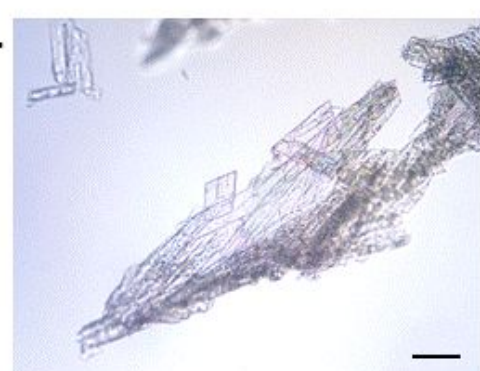

C.

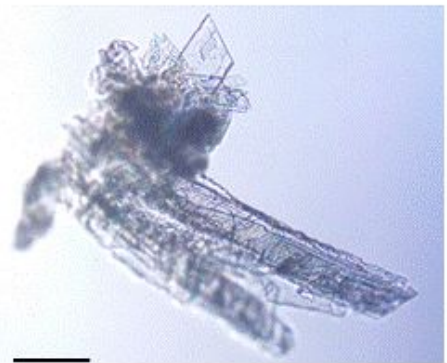

E.

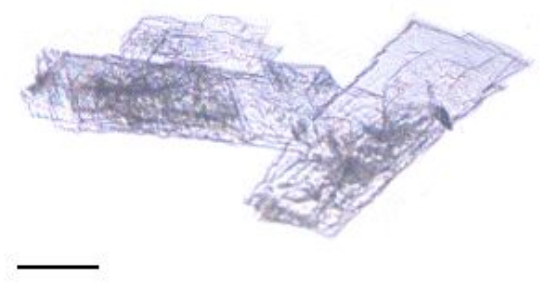

Figure S1. Representative micrographs of (a) TH, (b) TH-Ur $\mathbf{r}_{\mathbf{5}}$, (c) TH-Ur $\mathbf{r}_{\mathbf{1 0}}$, (d) $\mathbf{T H}-\mathbf{U} \mathbf{r}_{\mathbf{1 5}}$, (e) TH-Ur 20. All scale bars $=50 \mu \mathrm{m}$. 
<smiles>[H]</smiles>

Thymine<smiles>[2H]c1c(C)[nH]c(=O)[nH]c1=O</smiles>

uracil

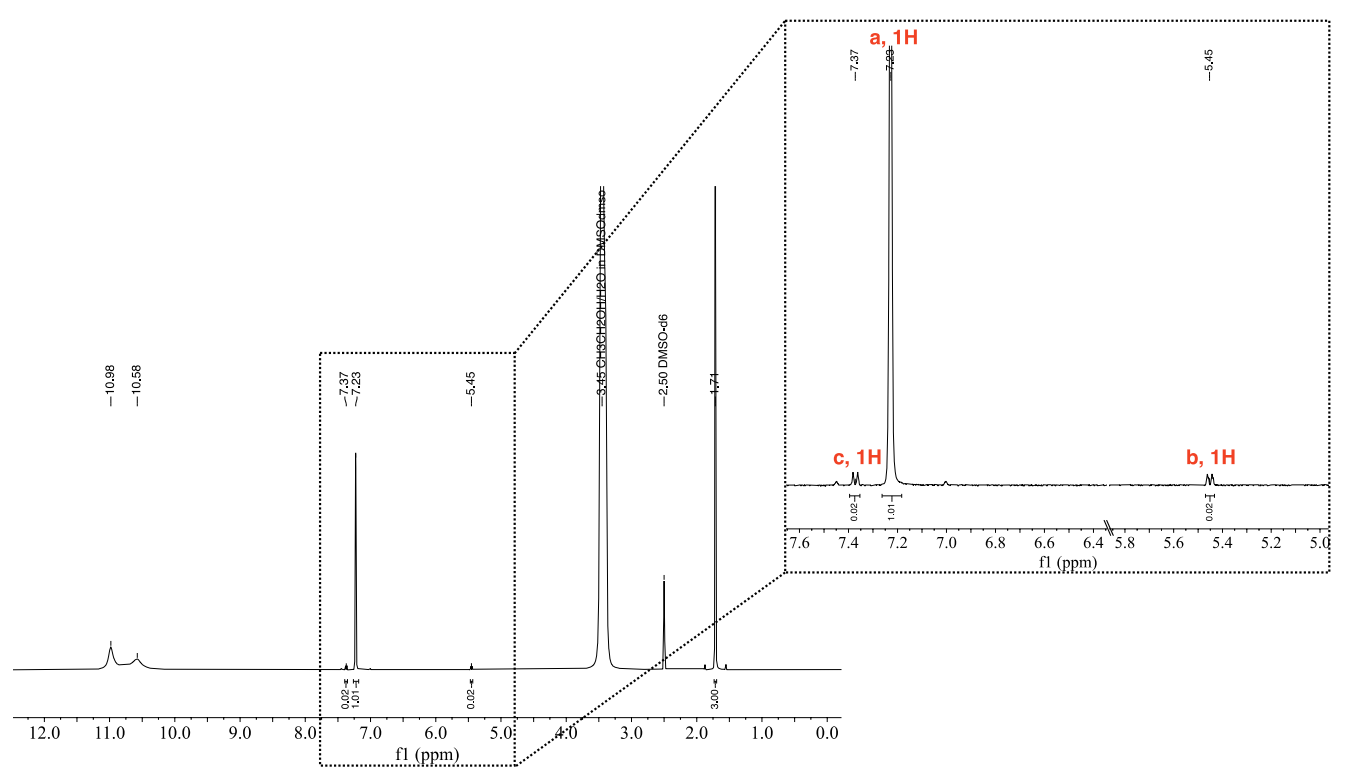

Figure S2. Representative ${ }^{1} \mathrm{H}$ NMR $\left(D M S O-\mathrm{d}_{6}\right)$ data for dissolved TH-Ur $\mathbf{r}_{\mathbf{5}}$. Hydrogen atoms in Ur at C5 and C6 have $\delta=5.44$ and 7.38, respectively. Integrated intensities were compared against the thymine peaks at $\delta=1.72$ and $\delta=7.24$. Average Ur occupancies in the hydrate lattices were used in the development of the X-ray structure models. 

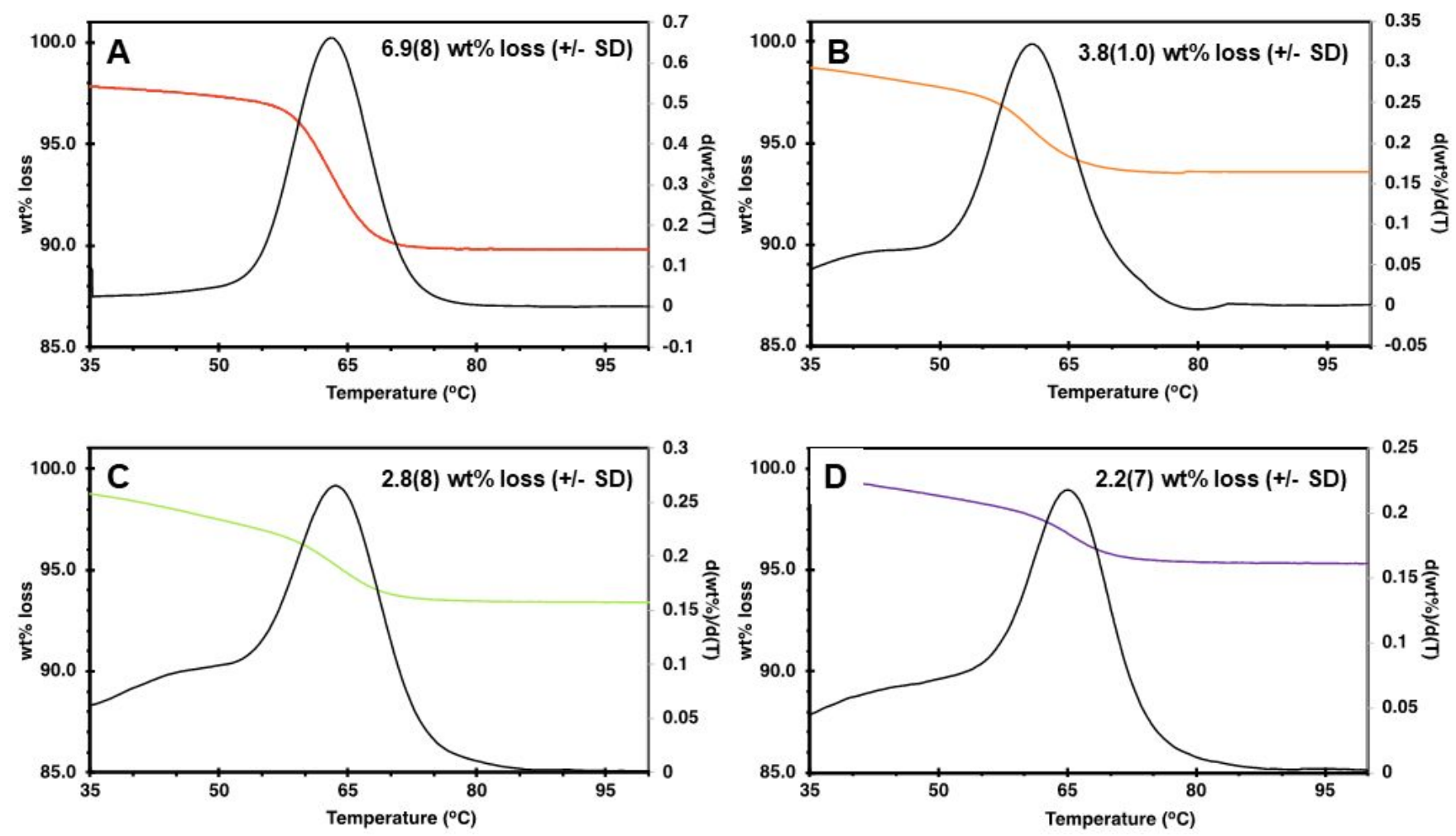

Figure S3. For material grown from solutions containing 5, 10, 15 and $20 \mathrm{~mol} \%$ uracil (A-D, respectively) the derivative method was used to determine when the greatest water loss occurs in TGA data. Weight losses decreasing from $~ 6.9(8) \%$ in $\mathbf{T H}-\mathbf{U r}_{5}$ to $2.2(7) \%$ in $\mathbf{T H}-\mathbf{U r}_{20}$ were obtained. However, these values do not account for water loss during sample preparation or at lower temperatures in the TGA run.

Table S1. Average $\mathrm{T}_{\max }$ determined in $\mathbf{T H}-\mathbf{U} \mathbf{r}_{\mathbf{x}}$ crystals grown from aqueous solutions with 5-20 mol\% Ur.

\begin{tabular}{cc}
\hline \multicolumn{2}{c}{ DSC $\mathbf{T}_{\max }$ values (Avg $\pm \mathbf{9 5 \%} \mathbf{C l}, \mathbf{n}>\mathbf{3}$ ) } \\
$\begin{array}{cc}\text { Ur in growth solution } \\
(\mathrm{mol} \%)\end{array}$ & Uracil \\
\hline 0 & $54.4(7)$ \\
5.0 & $59.9(1.3)$ \\
10.0 & $62.6(1.8)$ \\
15.0 & $63(2)$ \\
20.0 & $66.2(9)$ \\
\hline
\end{tabular}




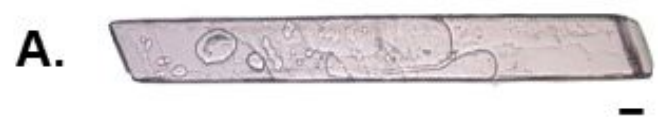

B.

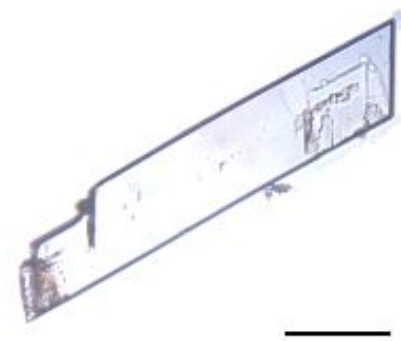

D.

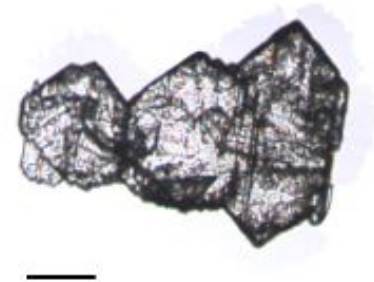

C.

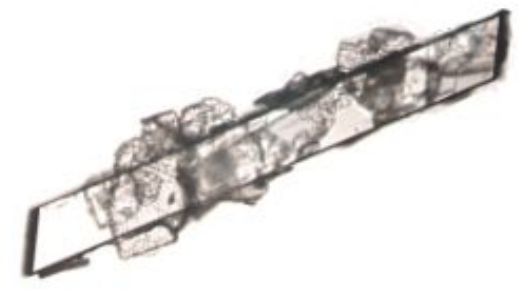

E.

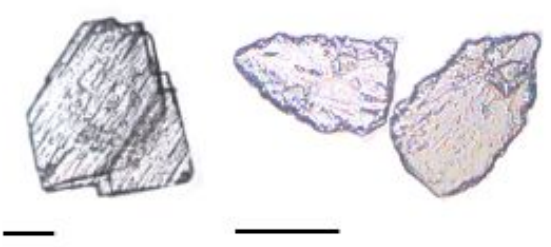

Figure S4. Representative micrographs of (a) TH, and mixed crystals grown from solutions with thymine and (b) 5 mol \% EUr, (c) 10 mol \% EUr, (d) 15 mol \% EUr and (e) 20 mol \% EUr. All scale bars $=50 \mu \mathrm{m}$. 
<smiles>[2H]Cc1c([2H])[nH]c(=O)[nH]c1=O</smiles>

Thymine<smiles>[2H]c1[nH]c(=O)[nH]c(=O)c1C([2H])([2H])[2H]</smiles>

5-ethyluracil

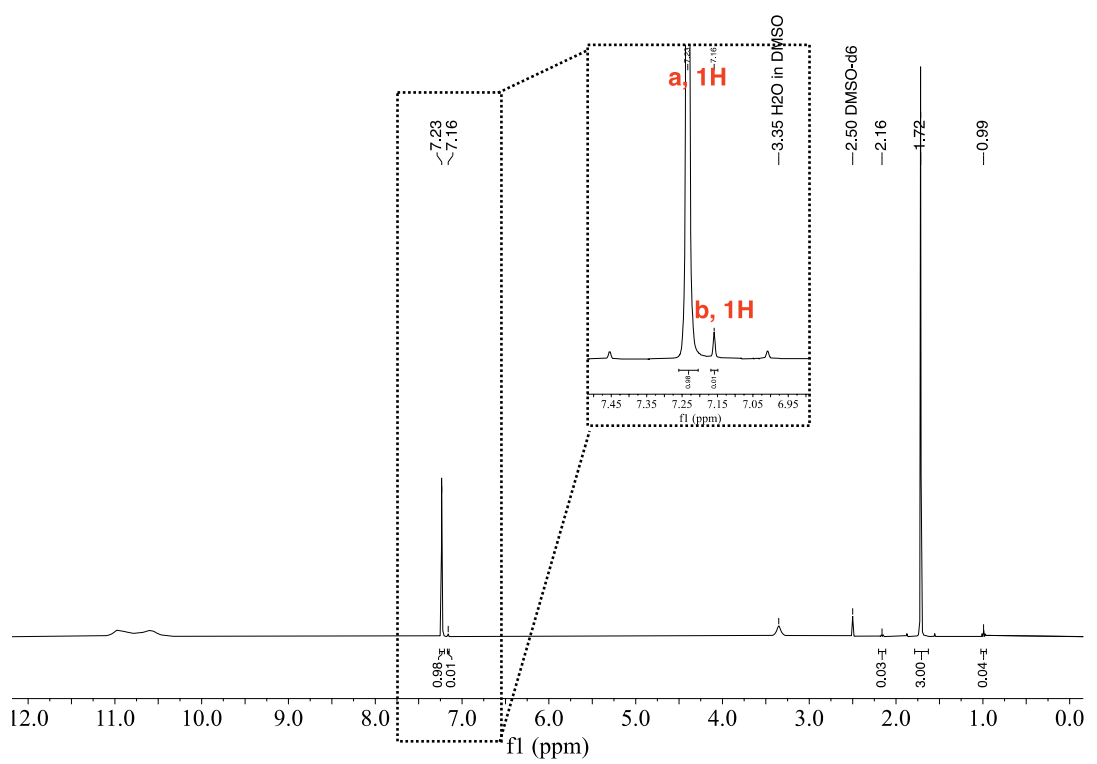

Figure S5. Representative ${ }^{1} \mathrm{H}$ NMR $\left(\mathrm{DMSO}^{-} \mathrm{d}_{6}\right)$ data for dissolved TH-EUr $\mathbf{r}_{5}$. The hydrogen atoms at $\mathrm{C} 6$ in thymine and EUr have $\delta=7.24$ and 7.19, respectively. Their relative integrated intensities were used in the development of the X-ray structure model. 

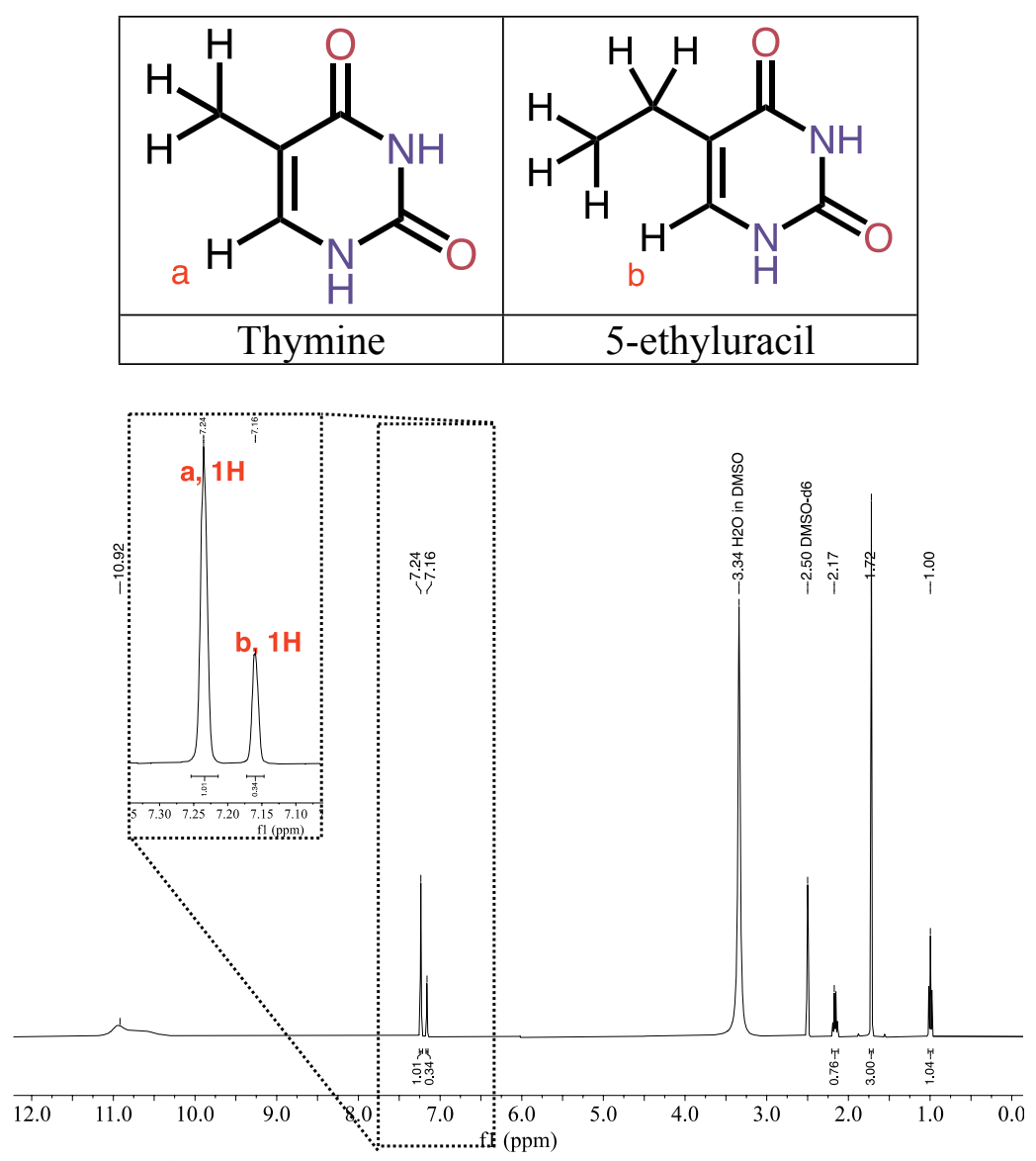

Figure S6. Representative ${ }^{1} \mathrm{H}$ NMR $\left(\mathrm{DMSO}^{-\mathrm{d}_{6}}\right)$ data for dissolved T-EUr $\mathbf{r}_{\mathbf{2 0}}$. The hydrogen atoms at C6 in thymine and EUr have $\delta=7.24$ and 7.19, respectively. Their relative integrated intensities were used in the development of the X-ray structure model. 


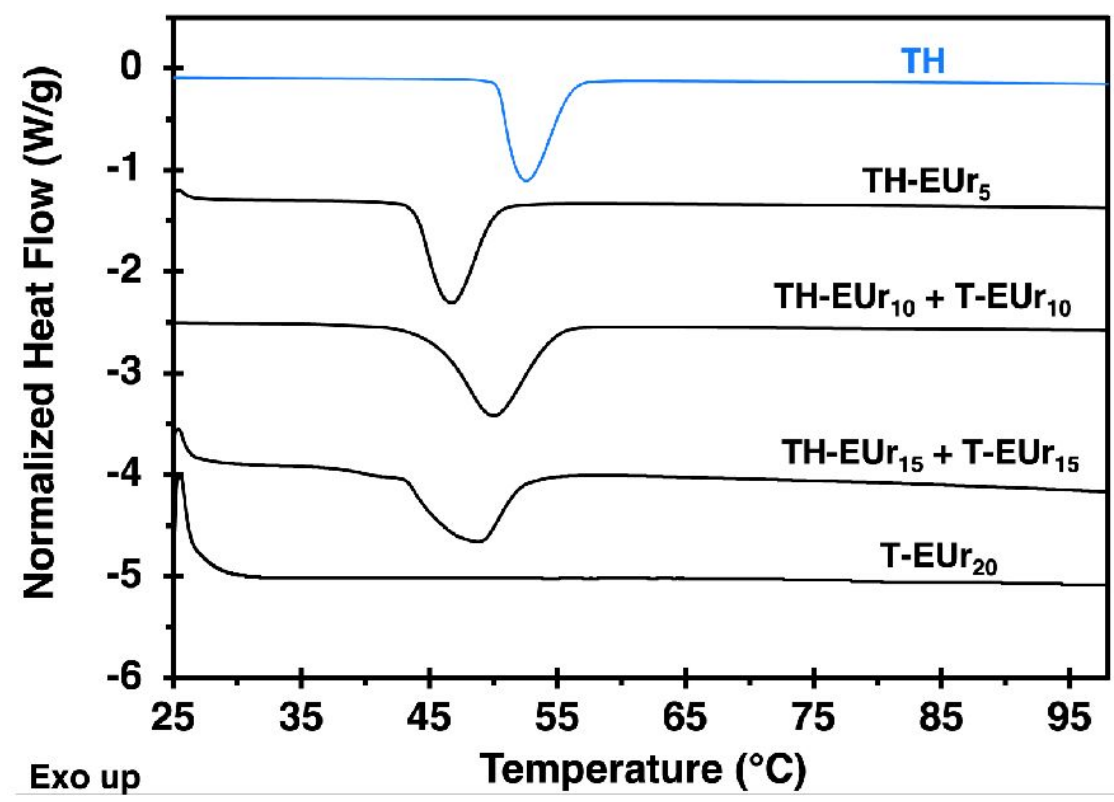

Figure S7. Differential scanning calorimetry of bulk material prepared from solutions containing $0-20 \mathrm{~mol} \%$ EUr. The phase composition is indicated for each. All measurements were made at $5.0^{\circ} \mathrm{C} / \mathrm{min}$ in hermetically sealed aluminum pans. 


\section{T-EUr 20}
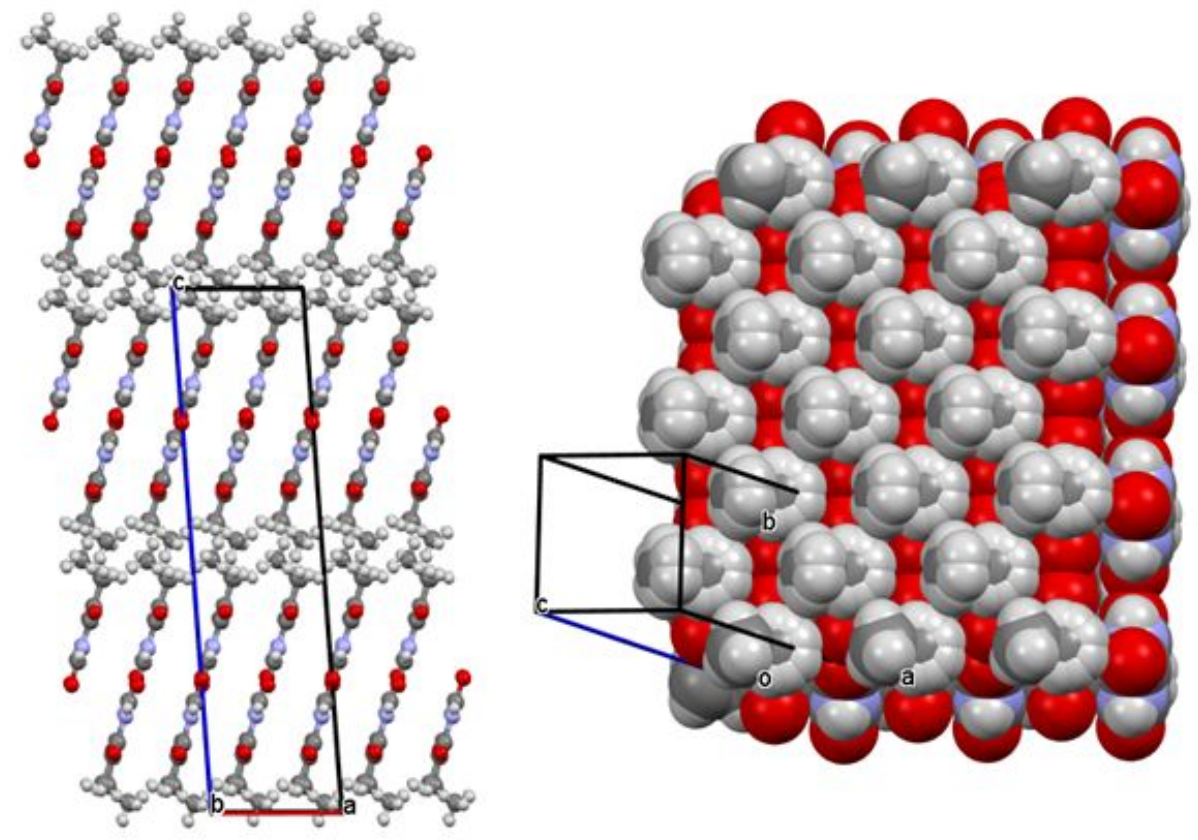

\section{5-ethyluracil (refcode: BOLLIY)}
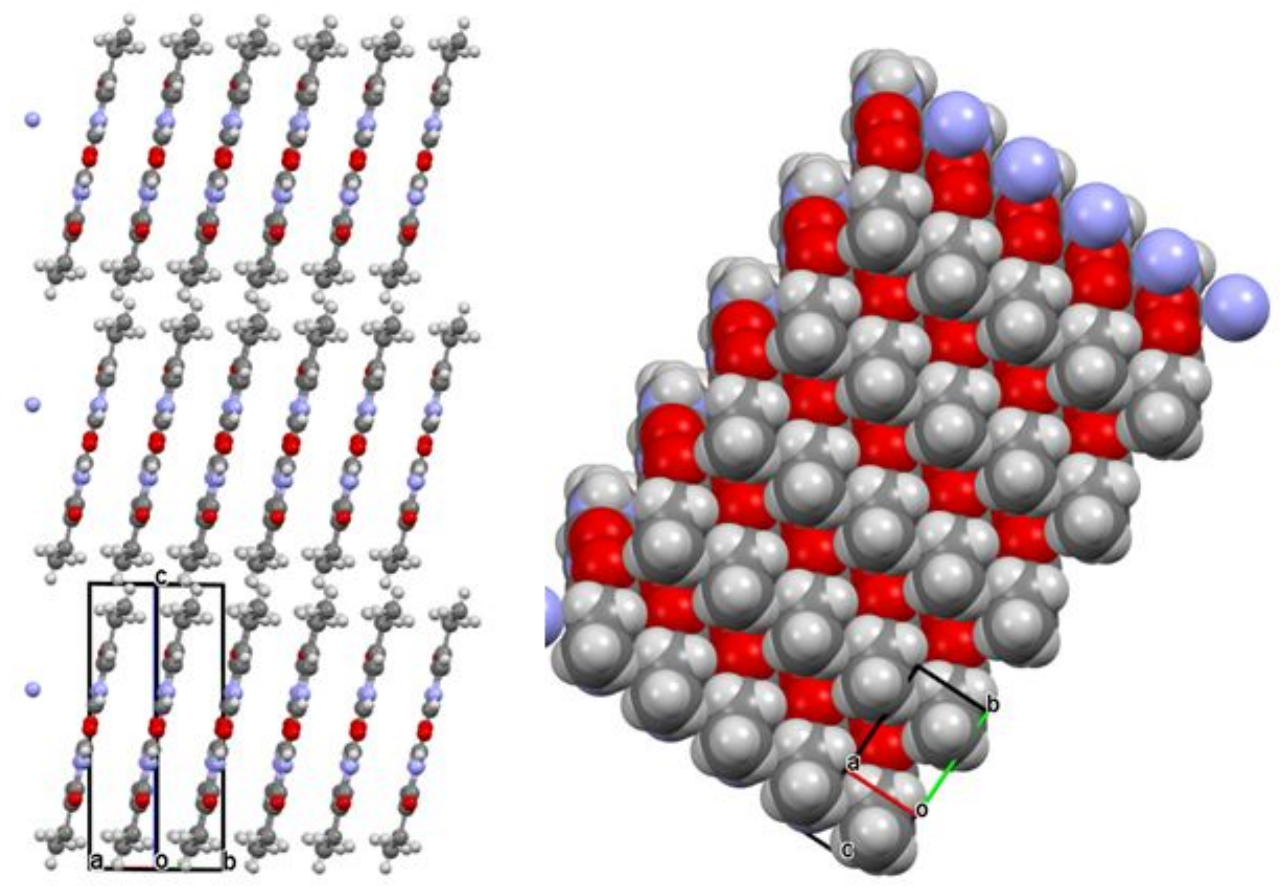

Figure S8. Side by side comparison of (top) T-EUr $\mathbf{r}_{20}$ and (bottom) 5-ethyluracil (refcode: BOLLIY). Two views of each structure are presented. The packing diagram on the left is viewed down the hydrogen bonded tape direction. The view on the right is normal to the (001) plane with the hydrogen bonded tapes aligned vertically. Space-filling is used to better illustrate the differences in the packing of the 5-ethyl substituents. 